\title{
ACTIVITY OF POLYHERBAL EXTRACT AGAINST BACTERIA CAUSING SKIN INFECTIONS IN DIABETIC PATIENTS
}

\author{
CHAITANYA SRAVANTHI KOTA ${ }^{1 *}$, HEMANTH KUMAR V ${ }^{2}$, SUNITHA REDDY ${ }^{1}$
}

${ }^{1}$ Department of Pharmacognosy, Centre for Pharmaceutical Sciences, IST, Jawaharlal Nehru Technological University, Hyderabad, Telangana, India. ²Department of Pharmacognosy, V.L. College of Pharmacy, Raichur, Karnataka, India. Email: sravanthikc@gmail.com

Received: 12 January 2017, Revised and Accepted: 13 February 2017

\section{ABSTRACT}

Objective: The objective of this study is to evaluate the antibacterial activity of polyherbal extract on few microorganisms causing skin infections in most of the diabetic patients.

Methods: Methanolic polyherbal extract was prepared from Acacia ferruginea (bark and fruit), Chloroxylon swietenia (bark, leaf, and root), Casearia elliptica (bark), and Terminalia alata (root, leaf). The preliminary phytochemical analysis was performed to identify the major phytoconstituents in the extract. The polyherbal extract was evaluated for antibacterial activity against bacteria such as Staphylococcus aureus, Bacillus subtilis, Pseudomonas aeruginosa, Escherichia coli, Proteus species, and Klebsiella species causing skin infections, diabetic foot infections in diabetic patients. In-vitro method of agar diffusion disc method was used for the evaluation of antibacterial activity through the zone of inhibition. The standard drug used was gentamicin. Minimum inhibitory concentration of the extract was done using the broth dilution method.

Results: The polyherbal extract showed good antibacterial activity. The standard drug used was gentamicin. The methanolic polyherbal extract showed potent activity on all the selected microorganisms. The polyherbal extract was active against P. aeruginosa (2.57 \pm 0.39 ) and $E$. coli (2.92 \pm 0.29 ) when compared with standard. The polyherbal extract showed potent activity on B.subtilis and Proteus vulgaris which are gram positive and gram negative bacteria respectively.

Conclusion: The polyherbal extract showed Broad spectrum antibacterial activity by being active against Gram-positive and Gram-negative microorganisms providing the scope for further analysis as an antibacterial preparation for the skin infections in diabetic patients.

Keywords: Antibacterial activity, Skin infections, Diabetes, Polyherbal extract, Agar diffusion disc.

(C) 2017 The Authors. Published by Innovare Academic Sciences Pvt Ltd. This is an open access article under the CC BY license (http://creativecommons. org/licenses/by/4. 0/) DOI: http://dx.doi.org/10.22159/ajpcr.2017.v10i5.17064

\section{INTRODUCTION}

Skin infections have become more common worldwide due to changes in the environmental conditions on the globe because of industrialization, pollution, deforestation, etc. Even though anyone is susceptible for skin infections, diabetic patients are more prone to such infections. Plants have been important sources of natural products for maintaining human health from ages. Skin is the protective and largest organ of humans [1]. Special care should be taken to protect this organ as it is easily prone in microbial attacks, effects of chemicals, radiations resulting into diseases [2]. Nowadays diabetes has become more common in human population, skin related problems have also increased in frequency as this group of population is more susceptible to the skin infections rather than normal group of population [3]. The most common skin problems are erypelas, carbuncles, and furuncles.

The natural sources have been an important source for mankind since evolution. Plants, animals, microbes, and minerals proved to be prominent sources of medicines for curing various diseases. The bacteria - such as Staphylococcus aureus, Bacillus subtilis, Pseudomonas aeruginosa, Escherichia coli, Proteus species, Klebsiella species, and Clostridium - reported to be common microbes in skin infections among diabetes patients. The skin of the foot is frequently infected by microbes [4].

The objective of the study is to prepare a polyherbal extract from traditionally claimed plants for antibacterial activity by following the in vitro method of microbial assay, i.e., agar diffusion disc plate method. A polyherbal extract was prepared from the plants with traditional uses claiming for antidiabetic and antimicrobial activity [5]. The plants selected for polyherbal extract preparation are Acacia ferruginea belonging to the family Leguminosea, Chloroxylon swietenia belonging to the family Rutaceae, Casearia elliptica belonging to family Flacourtiaceae, Terminalia alata belonging to family Combretaceae.

The selected plants may provide the new source of plant drugs to fight against the bacterial infections and also search for new chemical moieties of potent antibacterial activity.

The methanolic polyherbal extract was prepared from A. ferruginea (bark and fruit), C. swietenia (bark, leaf, root), C. elliptica (bark), and T. alata (root, leaf). The plant parts used for the preparation of extract were mentioned in literature from various sources [6-9].

\section{METHODS}

\section{Plant material}

The plants material required for extract preparation has been collected and authenticated by Dr. Madhava Chetty, Botanist, SVU, Andhra Pradesh, India. The plants material was collected, shade dried, and coarsely powdered.

\section{Plant extract preparation}

Methanolic polyherbal extract acacia, chloroxylon, casearia, terminalia extract was extracted from A. ferruginea (bark and fruit), C. swietenia (bark, leaf, root), C. elliptica (bark), T. alata (root, leaf) and evaluated for antibacterial activity. The powdered material of each plant was collected in equal quantity of $10 \mathrm{~g}$, i.e., $40 \mathrm{~g}$ of the plants material was taken for preparation of polyherbal extract, soaked in $150 \mathrm{ml}$ of methanol and macerated for $72 \mathrm{hrs}$ [10]. The solvent was decanted and subjected to rota evaporation to obtain the dried extract [11].

Preparation of test solution: The weighed amount of dried extract was dissolved in distilled water to make the required concentration. 


\section{Bacterial strains}

Test organisms used for the study are Gram-positive bacteria: $S$. aureus (MTCC740), B. subtilis (MTCC441) and Gram-negative bacteria: P. aeruginosa (MTCC424), E. coli (MTCC41), Klebsiella pneumonia (MTCC423), and Proteus vulgaris (MTCC426). All the strains were obtained from the Institute of Microbial Technology, Chandigarh, India. Microorganisms were cultured and maintained the culture in the laboratory conditions for further subcultures.

\section{Agar disc diffusion method}

In-vitro agar diffusion disc plate method was adopted to evaluate the antibacterial activity of the methanolic polyherbal extract. $24 \mathrm{hrs}$ cultures of above-mentioned organisms were freshly prepared and spread onto the sterile nutrient agar plates which were prepared by pouring $30 \mathrm{ml}$ of Muller-Hinton nutrient media into each sterile petri dish and left until hardened. Inoculums of each bacterium have been spread on Petri plates using swab uniformly and were incubated at $37^{\circ} \mathrm{C}$ for $24 \mathrm{hrs}[12,13]$. Discs were placed on the plates with concentrated extract of $50 \mathrm{mg} / \mathrm{ml}$ and gentamicin was taken as standard drug [14]. Gentamicin discs of $50 \mathrm{mg} / \mathrm{ml}$ are taken as standard for the experiment, allowed to stand for an hour to ensure proper diffusion and thereafter incubated for $24 \mathrm{hrs}$ at $35^{\circ} \mathrm{C}$. Antibacterial activity was determined by measurement of zone of inhibition around each disc in plate, using zone reader [15]. Measured inhibition zones were recorded as the diameter. This was repeated 6 times and average diameters were calculated.

\section{Preliminary phytochemical analysis}

Preliminary phytochemical tests were done according to the standard chemical screening tests [16]. The phytochemical constituents present in the polyherbal extract were detected following the methods described in standard books like Harborne [17].

\section{Statistical analysis}

The data obtained after determining the zone of inhibition was recorded and mean and standard deviation was calculated. Data have been expressed as mean \pm standard deviation. Statistical analysis was performed with GraphPad prism version 7.02 using ANOVA ( $\mathrm{p}<0.0001$ is considered to be significant).

\section{RESULTS AND DISCUSSION}

The percentage yield obtained after extraction process maceration was about $4.8 \%$. The preliminary phytochemical tests done on polyherbal formulation resulted in the presence of alkaloids, flavonoids, steroids, triterpenoids and phenolic compounds, etc.

\section{Phytochemical screening}

The phytochemical screening was done by chemical method in which the extract was tested by certain chemical tests. The extract showed the presence of major classes of secondary metabolites such as flavonoids, alkaloids, steroids, triterpenoids, terpenes, and phenolic constituents like tannins (Table 1) [18,19].

The antibacterial activity of extract has been assessed by agar disc diffusion method. The results were as shown in Table 2. The polyherbal extract showed varying activity on Gram-positive and Gram-negative bacteria.

Polyherbal extract $(50 \mathrm{mg} / \mathrm{ml})$ was found to be equally potent to Gentamicin (standard concentration $50 \mathrm{mg} / \mathrm{ml}$ ) against P. aeruginosa, B. subtilis, S. aureus, K. pneumoniae, and P. vulgaris. Activity index of the polyherbal extract was found to be equally potent to standard drug, and the observation showed that the polyherbal extract was active against both Gram-positive and Gram-negative organisms broad spectrum activity.

The polyherbal extract is more inhibitory on $B$. subtilis with mean zone of inhibition $3.3 \mathrm{~cm}$, followed by P. vulgaris, K. pneumoniae, Escherichia with near mean value of $2.9 \mathrm{~cm}$, Pseudomonas and Staphylococcus with mean $2.7 \mathrm{~cm}$. Standard drug was active against $P$. vugaris with mean
Table 1: Phytochemical constituents present in the polyherbal extract

\begin{tabular}{ll}
\hline Phytoconstituents & Occurrence \\
\hline Alkaloids & $+\mathrm{ve}$ \\
Flavonoids & $+\mathrm{ve}$ \\
Steroids & $+\mathrm{ve}$ \\
Triterpenoids & $+\mathrm{ve}$ \\
Phenolic compounds & $+\mathrm{ve}$ \\
\hline
\end{tabular}

+ve: Presence on phytoconstituent

Table 2: Mean diameter $(\mathrm{cm})$ or zone of inhibition of standard and polyherbal extract

\begin{tabular}{lll}
\hline Test organisms & \multicolumn{2}{l}{$\begin{array}{l}\text { Gentamicin standard polyherbal } \\
\text { extract }\end{array}$} \\
\hline P. vulgaris & $3.25 \pm 0.19$ & $3.22 \pm 0.36^{* * *}$ \\
K. pneumoniae & $2.6 \pm 0.66$ & $2.97 \pm 0.42^{* * *}$ \\
E. coli & $2.05 \pm 0.30$ & $2.92 \pm 0.29^{* * *}$ \\
P. aeroginosa & $2.03 \pm 0.49$ & $2.57 \pm 0.39^{* * *}$ \\
S. aureus & $2.1 \pm 0.30$ & $2.42 \pm 0.34^{* * *}$ \\
B. subtilis & $3.1 \pm 0.33$ & $3.3 \pm 0.35^{* * *}$ \\
\hline
\end{tabular}

$\mathrm{N}=6$; mean $\pm \mathrm{SD}$. ${ }^{* * *} \mathrm{p}<0.0001$ compared with gentamicin using two-way ANOVA test. SD: Standard deviation, P. vulgaris: Proteus vulgaris, K. pneumoniae: Klebsiella pneumoniae, E. coli: Escherichia coli, P. aeroginosa: Pseudomonas aeroginosa, S. aureus: Staphylococcus aureus, B. subtilis: Bacillus subtilis

of zone inhibition being $3.25 \mathrm{~cm}$, followed up with ascending order of activity by reporting next potent activity on $B$. subtilis $(3.1 \mathrm{~cm})$, K. pneumoniae, E. coli, Staphylococcus, and P. aeroginosa.

The antibacterial activity of the polyherbal extract may be due to the major chemical constituents present in the extract which are secondary metabolites present in the extract. The flavonoids reported in the extract may be one of the major constituent responsible for registering the antibacterial activity. Flavonoids have been reported as a major class of natural products with anti-infective activity. Many research showed that the structure of flavonoids and antibacterial activity have a close relationship [20]. The activity of flavonoid is due to inhibition of DNA.

\section{CONCLUSION}

Polyherbal extract has got potent antibacterial activity against few of the Gram-positive and Gram-negative microorganisms such as P. aeruginosa, B. subtilis, S. aureus, K. pneumoniae, and P. vulgaris. Phytochemical analysis has reported the presence of steroidal and phenolic compound in the extract. This study may give scope in the future to progress in the development of the herbal drug. Future research can fill some voids of this drug to consider.

\section{ACKNOWLEDGMENTS}

The author is thankful to the management of Vignan Institute of Pharmaceutical Sciences, HiMedia Chemicals for the support.

\section{REFERENCES}

1. Sheipouri D, Braidy N, Guillemin GJ. Kynurenine pathway in skin cells: Implications for UV-induced skin damage. Int J Tryptophan Res 2012;5:15-25

2. Anderson SE, Meade BJ. Potential health effects associated with dermal exposure to occupational chemicals. Environ Health Insights 2014;8(1):51-62

3. Wheat LJ. Infection and diabetes mellitus. Diabetes Care 1980;3(1):187-97.

4. Bader MS. Diabetic foot infection. Am Fam Physician 2008;78(1):71-9.

5. Biswajit P, Deenabandhu S, Malaya KM. Ethno-medicobotanical studies of Mohana area of Gajapati district, Odisha, India. Int J Herbal Med 2014;2(4):40-5. 
6. Duraipandiyan V, Ignacimuthu S. Antifungal activity of traditional medicinal plants from Tamil Nadu. Asian Pac J Trop Biomed 2011;1:204-15.

7. Umashanker M, Shruti S. Traditional Indian herbal medicine used as antipyretic, antiulcer, anti-diabetic and anticancer: A review. Int J Res Pharm Chem 2011;1(4):1152-9.

8. Ranjan S, Dasgupta N, Saha P, Rakshit M, Ramalingam C. Comparative study of antibacterial activity of garlic and cinnamon at different temperature and its application on preservation of fish. Adv Appl Sci Res 2012;3(1):495-501.

9. Chetty KM, Sivaji K, Rao K. Flowering Plants of Chittoor District. $1^{\text {st }}$ ed. Andhra Pradesh, India: Students Offset Printers; 2008.

10. Rangari V. Pharmacognosy and Phytochemistry. $3^{\text {rd }}$ ed. Nashik: Carrier Publishers; 2012. p. 103-10.

11. Kota CS, Bhargavi N, Kumar RA. Evaluation of antibacterial activity in Trigonella foenum graecum leaves. World J Pharm Res 2014;3(5):570-6.

12. Thomas SK, George RE, Kunjumon M, Thankamani V. In vitro antibacterial profile of Alstonia venenata $\mathrm{R}$. Br-A comparative study. Int J Curr Pharm Res 2015;7(4):86-8.

13. Goveas SW, Abraham A. Evaluation of antimicrobial and antioxidant activity of stem and leaf extracts of Coscinium fenestratum. Asian J
Pharm Clin Res 2013;6(3):218-21.

14. Jose B, Reddy J. Evaluation of antibacterial activity of the leaf and flower essential oils of Gliricidia sepium from south India. Int J Appl Pharm 2010;2(2):20-2.

15. Karunambigai A, Devi SG. Antibacterial activity of leaves and roots of Eclipta alba. Int J Pharm Pharm Sci 2014;6(1):454-6.

16. Hidayathulla S, Chandra KK, Chandrashekar KR. Phytochemical evaluation and antibacterial activity of Pterospermum diversifolium Blume. Int J Pharm Pharm Sci 2011;3(2):165-7.

17. Harborne JB. Phytochemical Methods: A Guide to Modern Techniques of Plant Analysis $3^{\text {rd }}$ ed. Berlin Heidelberg: Springer; 2005.

18. Akare SC, Sahare AY, Shende MA, Bondre AV, Wanjari AD. Hepatoprotective activity of Acacia ferruginea DC. leaves against carbon tetrachloride induced liver damage in rats. Int J Pharm Tech Res 2009;1(3):962-65

19. Rath S, Rabindra N, Padhy B. Monitoring in vitro antibacterial efficacy of Terminalia alata Heyne ex. Roth, against MDR enteropathogenic bacteria isolated from clinical samples. J Acute Med 2013;3(2):93-102.

20. Cushnie TP, Lamb AJ. Antimicrobial activity of flavonoids. Int $\mathrm{J}$ Antimicrob Agents 2005;26(5):343-56. 